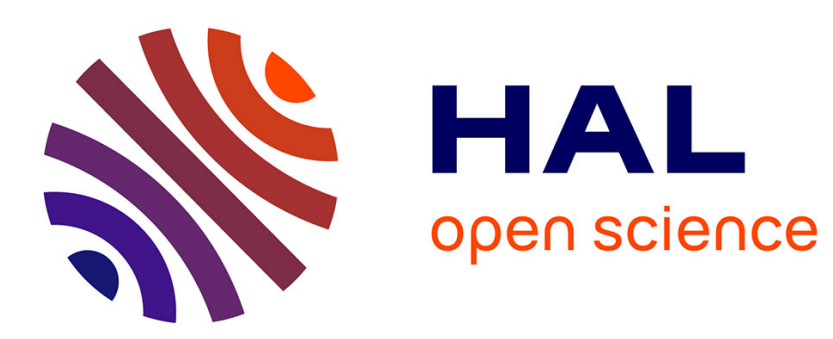

\title{
Personal Learning Environments as Enablers for Connectivist MOOCs
}

Denis Gillet

\section{To cite this version:}

Denis Gillet. Personal Learning Environments as Enablers for Connectivist MOOCs. Proceedings of the 12th International Conference on Information Technology Based Higher Education and Training, Oct 2013, Antalya, Turkey. pp.1-5. hal-00979391

\section{HAL Id: hal-00979391 \\ https://telearn.archives-ouvertes.fr/hal-00979391}

Submitted on 13 May 2014

HAL is a multi-disciplinary open access archive for the deposit and dissemination of scientific research documents, whether they are published or not. The documents may come from teaching and research institutions in France or abroad, or from public or private research centers.
L'archive ouverte pluridisciplinaire HAL, est destinée au dépôt et à la diffusion de documents scientifiques de niveau recherche, publiés ou non, émanant des établissements d'enseignement et de recherche français ou étrangers, des laboratoires publics ou privés. 


\title{
Personal Learning Environments as Enablers for Connectivist MOOCs
}

\author{
Denis Gillet \\ École Polytechnique Fédérale de Lausanne (EPFL) \\ Lausanne, Switzerland \\ denis.gillet@epfl.ch
}

\begin{abstract}
This paper presents how platforms initially designed to enable the construction of personal learning environments can help teachers and learners to aggregate their own MOOCs from resources freely available in the Cloud under Creative Commons licenses. Compare to the mainstream MOOC platforms like Coursera or EdX which are basically learning management systems open to external students, the proposed solution offers built-in social media features to boost opportunistic interaction and informal exchanges between students.
\end{abstract}

Keywords- Personal Learning Environments; PLE; Massive Open Online Courses; MOOCs; Connectivism; cMOOCs; Informal Learning; Lifelong Learning; Cloud

\section{INTRODUCTION}

In the framework of successive large-scale European research projects, a platform designed to support initially online communities of practice and later personal learning has been developed through participatory design and validated in higher education contexts. This platform named Graasp can be seen as a personal learning environment [1] (PLE) enabler, in the sense that it provides features to teachers and learners to easily find, aggregated and exploit individually or collaboratively learning resources delivered by their own institution or gathered from the cloud. It can also be seen as a project or knowledge management solution (KMS), in the sense that it facilitates the aggregation, sharing, repurposing and exploitation of knowledge artifacts in teams. Compared to learning management systems (LMS), such PLE platforms enforce a bottom-up approach for both the construction of the environment and the exploitation of the aggregated resources. These platforms have recently attracted interest from educators looking for agile solutions to develop connectivist MOOCs [2], referred as cMOOCs, which integrate built-in social media features to boost opportunistic interaction and informal exchanges between students.

In the rest of the paper, Section II details the concept of PLE and presents the Graasp PLE platform. Section III introduces Web Apps as a way to extend social media platforms with user-oriented services enabling the construction of PLE and cMOOCs. It also presents an inventory of generalpurpose apps relevant for education. Section IV provides a basic typology of the MOOC platforms. Finally, Section V introduces an example of a connectivist MOOC implemented in Graasp in the framework of an educational collaboration between Switzerland and French-speaking African countries.

\section{PLE AND PLE PLATFORM}

The concept of personal learning environments is not new. According to Wikipedia ${ }^{1}$, it was first coined in the 70 s. It was however rediscovered and consolidated with the emergence of the social Web (Web 2.0) that is enabling users to take the control of their online presence. The current conceptualization of a PLE (Fig. 1) is corresponding to shared online opportunistic and possibly ephemeral aggregation of communication channels, cloud resources, Web applications, and communities or peers (directly or through social media memberships), assembled in an agile way to define an interaction context for a given learning or knowledge management purpose, and accessed through interactive devices (computers, tablets, smart phones, ...).

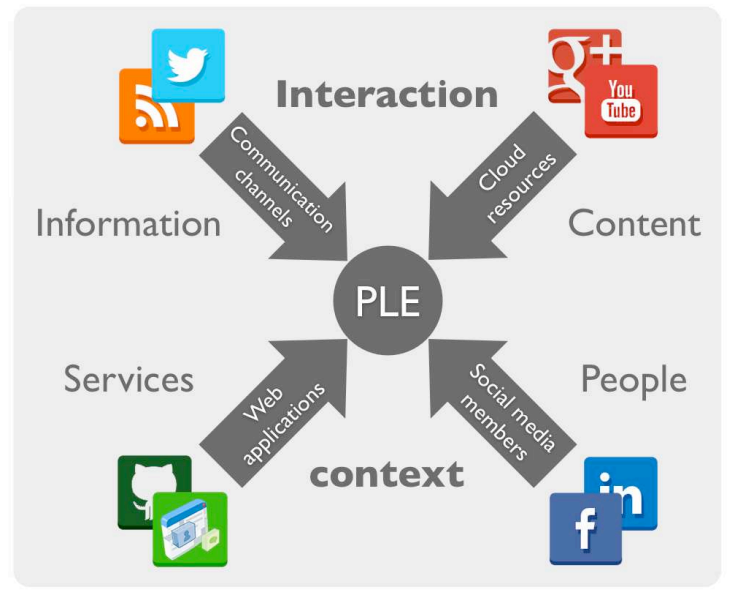

Fig. 1. The PLE as an aggregation of information, resources, services and people.

The possibility of adding Web apps in PLE when specific services are required is an important feature expanding constructivism from carrying out activities to designing the tools and the spaces to carry out these activities.

If one would stick on the PLE definition proposed above, there should be neither design nor implementation of platforms

${ }^{1}$ http://en.wikipedia.org/wiki/History_of_personal_learning_environments 
enabling the construction of personal learning environments. Any set of communication channels, cloud resources, Web apps and social media members assembled by a user would become a PLE. However, freely assembled ecosystems can hardly be stored, shared and repurposed by others. They also make the technical support and the educational coaching difficult. As a consequence, the EPFL has developed a dedicated social media platform called Graasp facilitating the aggregation and the exploitation of PLE as online contextual spaces. Such spaces are defined as the personal online places in which communication channels, cloud resources, Web apps and people are aggregated to support specific individual or shared activities. For the sake of symmetry in the way we treat the various entities being part of a PLE, we talk about the aggregation of people, which in fact means the ability of sharing the PLE with peers or experts and the possibility of repurposing it for collaborative usage. When dealing with entities gathered from the cloud, due to their plethora, search and recommendation features are required.

The core Graasp feature is to enable the creation and enforce the exploitation of dedicated online spaces as activity contexts (PLE). These spaces are defined, configured, shared and populated by users, for themselves and for the audience they choose. Graasp stands for grasping resources, apps, activity spaces and people. As a matter of fact, any space can embed subspaces supporting sub activities. However, hierarchy is not enforced. Users may decide to create either flat or hierarchical space structures to support their various learning or knowledge management activities. Graasp spaces can include members, resources, subspaces and apps. In addition, each entity has its own description implemented as a wiki enabling collaborative edition, a dedicated discussion thread, tags, and personal or public ratings; enforcing in such a way contextual exploitation. The connection with communication channels will be enforced in public spaces be providing in the next Graasp release the possibility to replace the built-in discussion thread by a twitter channel identified by a contextual hashtag. Other communication channels can be interfaced through Web apps as detailed in the next Section. The link with social media members is enabled by accepting login through Google+ or facebook OpenID.

In Graasp, there are three audience levels. Spaces can be public, i.e. visible to everybody, closed, i.e. restricted to their members (but external people can request membership) or hidden, i.e. only accessible by invited members. There are also three possible roles for the members of a space. They can be owner, which means that they can add or remove resources, as well as invite members or revoke memberships. The owner role can be assigned to more than one member of a space, which is a unique Graasp feature that enables to pass responsibilities over when required. People can be contributors, which means that that can add resources and can create subspaces for which they have the full control of the participants. Finally, people can be viewers, which means they can access but not alter the content of a space. They can however post comments; which is an important part of the asynchronous interaction in shared online activities. The agile aggregation of cloud resources is supported by an open source plugin architecture and implemented as a GraaspIt! bookmarklet which enables a one- click aggregation of external resources in the Graasp clipboard for further integration in spaces.

Figure 2 shows a space defined in Graasp for a specific activity and integrating members (labeled in blue), apps (labeled in pink) providing additional features like a wiki or a translator, as well as resources (labeled in green) collected from the Cloud (documents or bookmarks with previews). Any type of entity, including subspaces, can be created or added by using the big multicolor Graasp hand (either by clicking or dragging and dropping objects on it).

The Graasp platform has been developed through participatory design and validated in various test beds [3]. In higher education, Graasp turned out to be effective to support teacher communities sharing educational resources and best practices. It was also effective to facilitate the setting up and the running of collaborative learning activities. The agile space creation process enables to get rid of system managers and to let students organize themselves more freely. Last but not least, it enables to develop and to practice IT literacy and autonomy, which are among the most important soft skills in our $21 \mathrm{st}$ century knowledge society. As a matter of fact, the platform has been also exploited to run soft skill workshops for doctoral candidate focusing on the search and exploitation of digital resources (especially scientific references), digital intellectual property rights, as well as Science 2.0 practices using PLE platforms and other Web 2.0 tools.

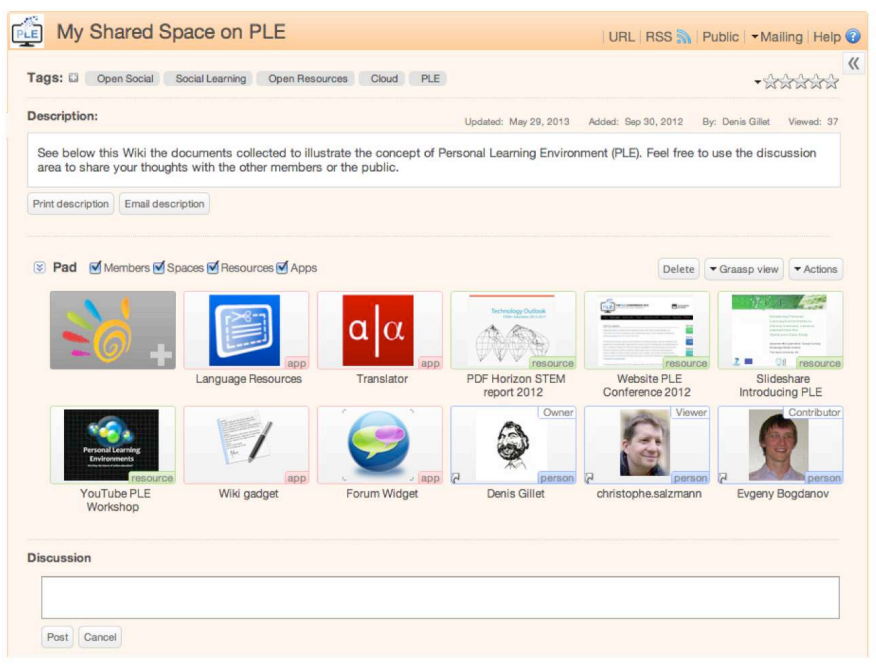

Fig. 2. An online contextual space aggregated, hosted and exploited collaboratively in Graasp.

In order to facilitate the open sharing of resources and awareness, Graasp automatically proposes Creative Commons ${ }^{2}$ licenses when content is made available in public spaces [4]. This feature is somehow also an enabler for a paradigm change in the exchange of information. By offering an easy way to add Creative Commons licenses, people are encouraged to share their resources freely in the cloud and to repurpose and valorize them in groups or communities, which is an essential feature to support cMOOCs. 


\section{WEB APPS}

Relying on Web apps is an interesting means to provide additional end-user services in social media or PLE platforms. It is also and interesting software engineering approach enabling to limit development efforts to core platform features. Finally, code developed as Web app can be reused more easily. Currently, the most interesting standard to develop Web apps, also referred to as gadgets or widgets, is OpenSocial ${ }^{3}$, which was initially created for the iGoogle platform and which is now adopted by other social media platforms and open source projects. OpenSocial Web apps can be located anywhere in the Web and added directly in social media platforms by the users themselves using a simple URL, providing that these platforms integrate the Apache Shindig ${ }^{4}$ open source container.

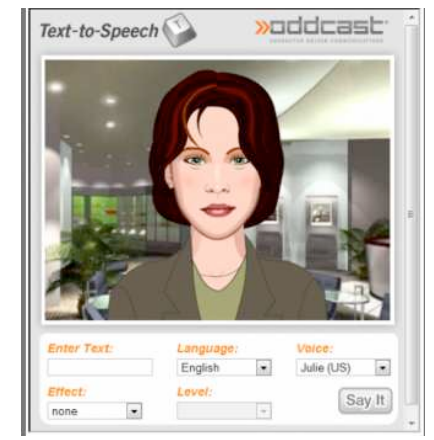

Fig. 3. A simple OpenSocial text-to-speech Web app

Web apps can offer simple feature like a text-to-speech translator (Fig. 3), or fully-featured services like the iPlotz mockup design application (Fig. 4). General-purpose repositories of OpenSocial Web apps exist, like iGoogle ${ }^{5}$, as well as more domain-oriented ones like the ROLE Widget Store $^{6}$ targeting only education.

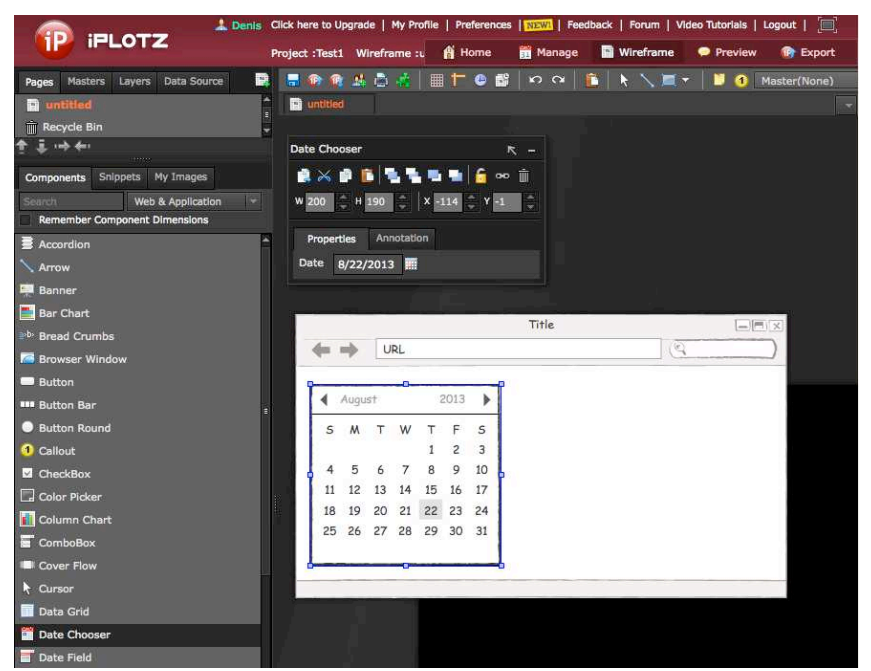

Fig. 4. A fully-featured OpenSocial mockup Web app.

\footnotetext{
${ }^{3}$ http://opensocial.org

${ }^{4}$ http://shindig.apache.org

${ }^{5} \mathrm{http}: / / \mathrm{www}$. google.com/ig/directory

${ }^{6} \mathrm{http}: / /$ www.role-widgetstore.eu
}

In education, three main categories of Web apps can be considered. General-purpose apps providing features like a wiki editor, a discussion forum, a dictionary or a calculator can be helpful for a large set of activities. Dedicated support apps can provide scaffolding for targeted user groups like kids or specific activities like teamwork. An activity-planning app or learning analytics and progress awareness apps belong to this category. Content wrapper apps are domain-specific and enable the delivery of preselected content. As example, an iFrame app (Fig. 5) enables the delivery of any external Web page within a contextual interaction space.

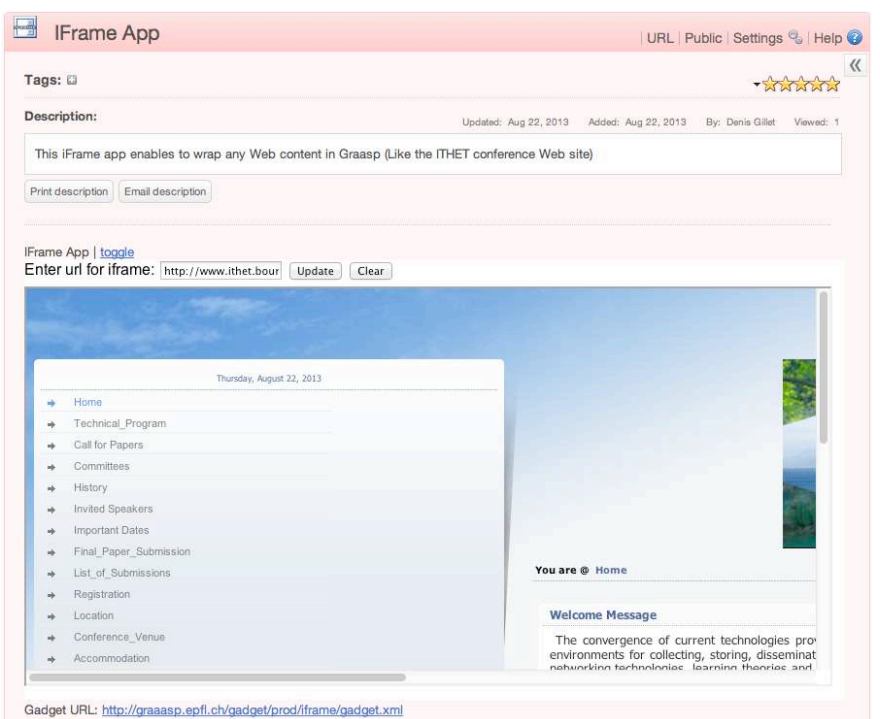

Fig. 5. An OpenSocial iFrame Web app integrated in Graasp to embed an external Web page in a PLE.

Web apps can be exploited in a PLE platform to enable the creation of connectivist MOOCs as it is detailed in the next Section, by offering different dedicated services in each contextual interaction space.

\section{TyPOLOGY OF MOOC PLATFORMS}

Mainstream MOOC platforms like Coursera and EdX do not really differ from classical LMS. The main differences are that MOOC platforms are accessible worldwide by anyone, are able to handle hundreds of thousands of students simultaneously, and usually support peer evaluation (the main recent educational innovation in the e-Learning field). As LMS, MOOCs platforms enforce teacher- and session-driven activities to be carried out with preselected resources at a specific time; the resources being in this case mainly short video sequences of about $15 \mathrm{~min}$ with associated quizzes delivered weekly on a semester basis.

Kop et al. [5] highlighted that a connectivist course is based on four major types of activity, i.e. Aggregation, Remixing, Repurposing, and Sharing, which are the typical actions supported by a PLE platform. MOOC and cMOOCs are not dichotomous concepts. There is a large continuum of possible intermediary MOOC implementations ranging from a MOOC fully controlled by the platform provider and a one fully controlled by the participants. Building on this observation, we 
can distinguish three dimensions to characterize this continuum from MOOCs to cMOOCs:

- Aggregation \& Dissemination Features: From related actions driven by providers to contributions shared by participants;

- Coaching \& Assessment Features: From related normative activities supervised by teachers to formative interactions handled collaboratively with peers;

- Timing \& Structuring Features: From related scaffolds enforced by the platforms to sequences and relations controlled by the participants.

Even in cMOOCs, enforcing a delivery through regularly scheduled sessions may be beneficial as a self-directed learning scaffold keeping motivation high enough to avoid drop out. In connectivist MOOCs, however, the pace is not necessary synchronized with a weekly schedule and the delivery not spread over a semester. It could also be concentrated on a full week and initiated at any time. One of the main criticisms of mainstream MOOCs is that students have to wait sometime for weeks before being able to follow selected courses. Such a constraint is incompatible with typical lifelong learning patterns requiring flexibility. Another criticism is that the students cannot access anymore the educational material and discussion traces after completion.

Connectivist MOOCs do not necessary rely on specific platforms, as they often results from self-directed aggregation of resources and tools. However, the previous statements clearly show how a PLE platform can be instrumental is setting up or getting involved in cMOOCs. Even so, some features are missing to let teachers or students provide fully-featured MOOC or cMOOC support. Discussion with interested parties involved in the RESCIF Network of Excellence ${ }^{7}$ in Engineering Sciences of the French-speaking countries have highlighted that the following features are especially required:

- Peer evaluation support;

- Creation of quizzes, collection of the answers and analysis;

- Team building and competence bartering support;

- Formalization of time-based and topic-based structures through spaces (timing and navigation) using tables of content, syllabuses or calendars for navigation and exploration;

- Support of additional metadata through internal tags (automatically identified or inherited from domain ontologies) to ease search and recommendation;

- Customization of the portal spaces hosting cMOOCs with graphical templates enforcing branding or group identity building;

- Management of multilingual resources (Wikipedia model) supporting a given activity to broaden sharing opportunities with developing and emerging countries;
- Tagging and subtitling of video sequences;

- Online recording and editing of video sequences;

- Integration of e-texbook standard documents (epub3).

These features can however be provided as specialized Web apps. Once integrated in a space dedicated to a cMOOC, these apps are accessible to all members, can be personalized and can store or retrieve information related and resources belonging to this space. As a consequence, limited development efforts can turn a PLE platform into a cMOOC platform.

When relying on a PLE platform, a cMOOCs implementation facilitates the co-production and coexploitation of content between different teachers which can provide only materials directly related to their core expertize and rely on colleagues from other institutions for additional open educational resources (OER). Such an approach implemented using a mainstream platform would require challenging intellectual property right negotiations and bilateral conventions for exploitation. As such, the PLE platform not only enables to flip the classrooms (by freeing classroom time for personal interaction), but also to flip the institutions (by redefining the educational mission towards collaborative highquality content edition and accreditation).

\section{EXAmple of A Personal cMOOC}

As a prototypal example, one can consider the scenario of a Swiss and an African teacher offering together a join course on Social Media as a cMOOC. One of the objectives of the course is to enable the creation of distributed teams of developers and designers through the informal contacts established between participants in the framework of the course, as well as to boost the local economy by creating international business opportunities in this high potential social media market.

The core part of the course consists of YouTube educational videos offered freely by the academic communities. The two teachers contribute by selecting video sequences related to the mobile application design approaches and agile development methodologies, which correspond to their respective domain of expertize. The idea is also to let the participants contribute with additional resources, which will be recommended according to their rating by the peers. Largescale teamwork activities aiming at establishing participatory design teams to design and prototype social applications are also proposed for students having already explored the course materials. The teams are formed in an opportunistic way by students, which are explicitly stating that they are looking for teammates to work during a specific period. As the audience of the cMOOC is quite large, there are always enough students at the same stage in the course able to work together. They choose collaboratively a social app to design, carry out the prototyping work and post their contribution openly at the end on a crowdsourcing platform for evaluation by the community and hopefully to get funding for development.

The Graasp portal space created to host the proposed cMOOC is represented in Figure 6. Subspaces integrated the

\footnotetext{
${ }^{7} \mathrm{http}: / /$ www.rescif.net/en/rescif
} 
various video sequences aggregated from the cloud using GraaspIt! are also visible.

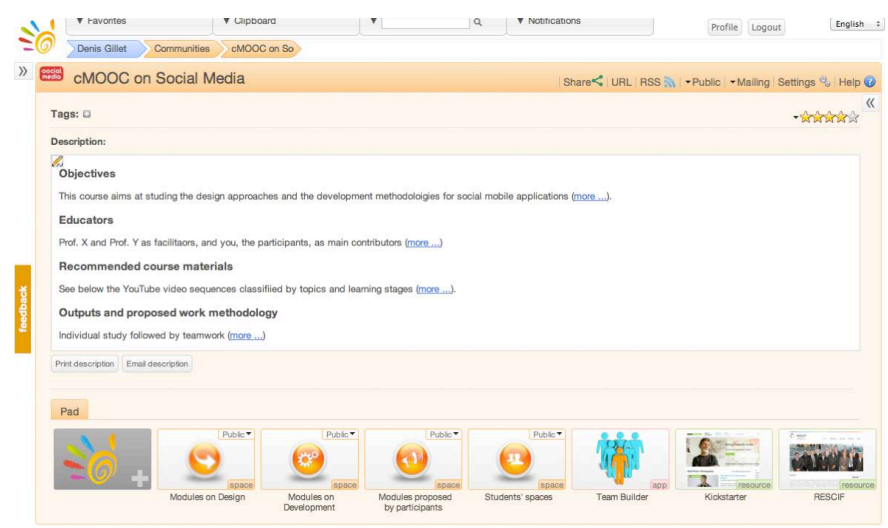

Fig. 6. The cMOOCs portal implemented in Graasp with dedicted spaces, apps and resources provided, organized and exploited collaboratively by teachers and students.

One of the subspaces is detailed in Figure 7. It is populated by students with interesting YouTube video sequences related to the course. They can be viewed from within the space in the resource view mode. Other personal or shared subspaces have been created by the participants for their teamwork in the Students' space.

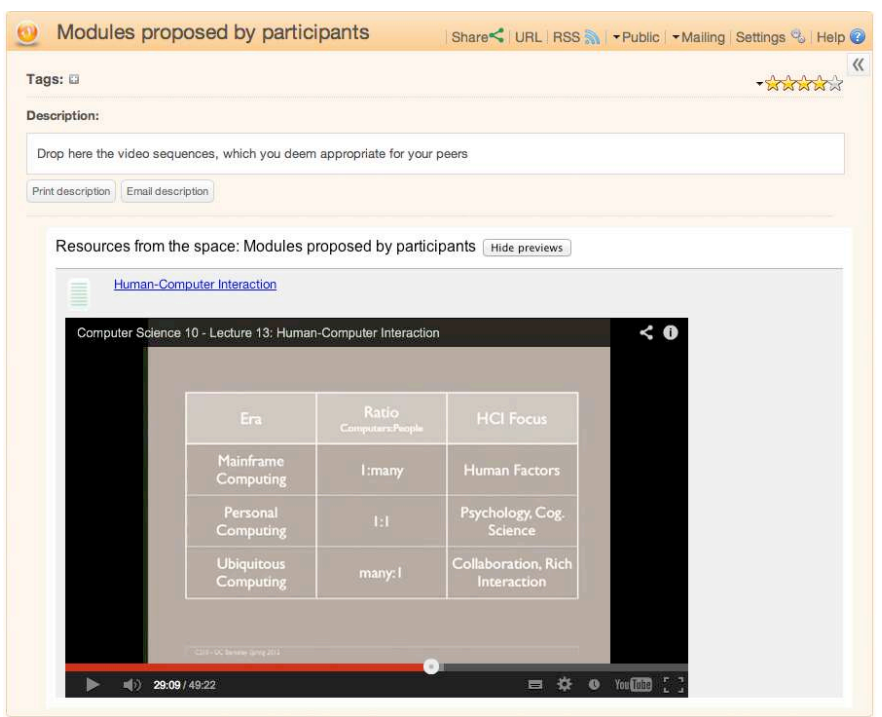

Fig. 7. A dedicated space with interesting YouTube educational video sequences populated by students.

Web apps are also recommended. However, most of the time the students aggregate the services they like autonomously in their own spaces. The crowdsourcing platform is bookmarked at the first level in the portal, where the students also find a dedicated app to help them in creating the groups. As matter of fact, this application has been designed by one of the first group having completed the course.

This example shows that the proposed PLE platform can easily accommodate the creation, the hosting and the exploitation of a cMOOC portal.

\section{CONCLUDING REMARKS}

PLE platforms being initially designed for fully selfregulated learning activities, they provide neither session-based delivery of content at specific time, nor peer evaluation tools. They however offer built-in social media features enabling easy and opportunistic collaboration and interaction, such as federated social media communication channels and cloud aggregation of open resources shared under Creative Commons licenses. Fortunately, PLE platforms support not only the aggregation and the mashup of content, but also the aggregation of Web apps extending the basic features by external end-user interactive services.

\section{ACKNOWLEDGMENT}

This work was partially funded by the European Union in the context of the ROLE (Grant Agreement no. 231396) and Go-Lab (Grant Agreement no. 317601) projects under the Information and Communication Technologies (ICT) theme of the 7th Framework Programme for R\&D (FP7), as well as the Learning Infrastructure of the Swiss CUS programme P-2 on Scientific Information: Access, Processing, and Storage.

\section{REFERENCES}

[1] D. Gillet, E. Law and A. Chatterjee, "Personal Learning Environments in a Global Higher Engineering Education Web 2.0 Realm," Global Engineering Education Engineering (EDUCON), Madrid, Spain, April $14-16,2010$.

[2] Connectivist MOOCs, visited on June 27, 2013, http://www.connectivistmoocs.org.

[3] E. Bogdanov, F. Limpens, N. Li, S. El Helou and C. Salzmann, "A Social Media Platform in Higher Education," Global Engineering Education Conference (EDUCON), Marrakesh, Morocco, April 17-20, 2012.

[4] D. Gillet and E. Bogdanov, "Cloud-Savvy Contextual Spaces as Agile Personal Learning Environments or Informal Knowledge Management Solutions," 12th International Conference on Information Technology Based Higher Education and Training (ITHET), Antalya, Turkey, October 10-12, 2013.

[5] R. Kop, H. Fournier, and S.F. J. Mak, "A Pedagogy of Abundance or a Pedagogy to Support Human Beings? Participant Support on Massive Open Online Courses.” The International Review of Research in Open and Distance Learning. Vol 12, No. 7, 2011. 